\title{
Continuous Descent Approaches with Variable Flight-Path Angles under Time Constraints
}

\author{
R. Sopjes*, P.M.A. de Jong†, C. Borst $\ddagger$ M.M. van Paassen ${ }^{\S}$ \\ M. Mulder $\llbracket$ \\ Delft University of Technology, P.O. Box 5058, 2600 GB Delft, The Netherlands
}

\begin{abstract}
In order to reduce noise nuisance around Schiphol Airport, a Continuous Descent Approach procedure was introduced in the late '90s. Unfortunately, because unpredictable individual aircraft behavior lead to increased landing intervals for this procedure, it is currently only applied during night time operations. Time-of-Arrival control in the terminal area could reduce the landing interval for this procedure. The research presented in this paper investigates the influence of multiple segments with different flight-path angles on the time of arrival. A new procedure with Variable Flight-path angle (VFA) involving active planning of the approach from the pilot through a pilot support interface, presented in the Vertical Situation Display. A preliminary pilotin-the-loop evaluation was conducted, to investigate pilot performance, workload and interface usability. Three scenarios were tested, all with different Required Time of Arrival. Workload was low for all scenarios and performance good for the two scenarios with early arrival times. For the scenario with a late arrival time, performance was mediocre. Changes in representation of the flap and gear cues and the addition of Estimated Time of Arrival information might improve the performance.
\end{abstract}

\section{Introduction}

Aircraft noise near airports is an increasing problem for major airports around the world. ${ }^{1}$ This is caused by an increasing number of arriving and departing flights and the fact that many major airports are surrounded by large, densely populated residential areas (e.g., Schiphol Airport, Los Angeles Airport, London Heathrow).

In order to reduce the noise impact on the ground, and to reduce the amount of greenhouse gases emitted, Noise Abatement Procedures (NAPs) can be introduced. These NAPs became applicable after the introduction of new aircraft systems, such as Global Positioning System (GPS) and modern Flight Management Systems (FMSs).

An NAP already in use today at Schiphol Airport is the Continuous Descent Approach (CDA). This procedure starts from an Initial Approach Fix (IAF) at approximately 10,000 ft above ground level. Then, the aircraft starts its descent in such a way that the Instrument Landing System (ILS) intercept point is reached at $3,400 \mathrm{ft}$ with idle or near idle power setting. The disadvantage of the Continuous Descent Approach (CDA) is that the landing interval has to be increased from 1.8 to 4 minutes. ${ }^{2}$ This increased landing interval is due to the large dispersion in aircraft approach speeds. A consequence of this increased landing interval is that, for instance, at Schiphol Airport, CDAs are only executed at night, when traffic density is low.

To overcome the problem of an increased landing interval, numerous other NAPs have been developed as well. These procedures use two different methods to adapt the time duration of the approach procedure.

\footnotetext{
*MSc-Student, Control and Simulation Division, Faculty of Aerospace Engineering, Delft University of Technology

${ }^{\dagger}$ PhD-Student, Control and Simulation Division, Faculty of Aerospace Engineering, Delft University of Technology. Kluyverweg 1, 2629 HS Delft, The Netherlands. AIAA Student Member. E-mail: p.m.a.dejong@tudelft.nl

${ }^{\ddagger}$ Research Associate, Control and Simulation Division, Faculty of Aerospace Engineering, Delft University of Technology, AIAA Member

$\S$ Associate Professor, Control and Simulation Division, Faculty of Aerospace Engineering, Delft University of Technology, AIAA Member

ๆ Professor, Control and Simulation Division, Faculty of Aerospace Engineering, Delft University of Technology, AIAA Senior Member
} 
For the first method, the lateral and vertical path is fixed, all the way from the top of descent to the runway. The first procedure that used this method, is the Advanced Continuous Descent Approach (ACDA). ${ }^{3}$ For an ACDA, the vertical path is fixed to a $3^{\circ}$ glide path. The FMS is used to plan and execute a full $4 \mathrm{D}$ trajectory. In order to meet the $4 \mathrm{D}$ trajectory requirements, the timing of the configuration change points (flap and gear) has to be taken into account in the calculations.

Another procedure that keeps the lateral path fixed and the vertical path fixed to $3^{\circ}$, is the ThreeDegree Decelerating Approach (TDDA). ${ }^{4}$ For this procedure, variation of the time duration is again achieved by adapting the flap schedule. ${ }^{5-9}$ However, for this procedure, the task of separation is left to the pilot by means of self-separation. The adaptation of the flap schedule for this procedure, means that the speeds for which the next flap setting must be selected, can be different for each approach. A disadvantage of this method is that these changing flap speeds might be confusing for the pilots. Also, when the flaps are extended at higher speeds, this might introduce problems with flap wear and passenger comfort. $^{10}$

The second method keeps the flap schedule constant and variation in duration of the approach procedure is achieved by adapting the vertical path flown by the aircraft. An NAP that uses this method is the Free Degree Decelerating Approach (FDDA).${ }^{10}$ This procedure uses the FMS to plan the vertical trajectory the aircraft has to fly. Because the current mode of operation of Air Traffic Control (ATC) is tactical and sector specific, additional speed or altitude constraints are often given to pilots during execution of the trajectory calculated by the FMS. To implement these new constraints, significant pilot input on the Control Display Unit (CDU) of the FMS is necessary. In some cases, the FMS is not functionally capable of incorporating these constraints, due to differences in trajectory generation techniques between ATC and FMS systems. In that case, pilots have to disconnect their FMS's Lateral Navigation (LNAV) and Vertical Navigation (VNAV) functions and revert to other Autopilot (A/P) modes. $^{11}$

The goal of this research is to develop a new approach procedure, the Variable Flight-path angle Approach (VFA), that keeps the flap schedule constant, but does not necessarily require the LNAV and VNAV mode of the FMS to execute the approach. The advantage of this, is that the pilot can revert to more tactical A/P modes, when he has to disconnect the FMS A/P modes, without the loss of performance. The lateral path is kept fixed, and the only variable is the vertical path of the aircraft. To assist the pilot in determining the ideal approach profile, use will be made of the Vertical Situation Display (VSD) to plan, alter and preview the approach path and its control settings.

To investigate Required Time of Arrival (RTA) performance, pilot workload and interface usability of the Variable Flight-path angle Approach (VFA), a preliminary pilot-in-the-loop evaluation was conducted. Each of the four subjects was asked to execute five, straight-in approaches: two training runs and three scenarios with different RTA. Each run started at a distance of 65 NM before the runway, with the aircraft trimmed at 10,000 ft and 250 KIAS. The scenarios consisted of a slow, an intermediate and a fast approach. The difference between Actual Time of Arrival (ATA) and RTA was measured for each run as an indication for pilot performance.

This paper is structured as follows. First, an overview of previous research on various NAPs is given in Section II. Second, the VFA is introduced in Section III. This section also contains the results of offline simulations that were performed in MATLAB. The designed pilot support interface is given in Section IV. At last, the experiment and its results are discussed in Section V.

\section{Background}

When aircraft enter Amsterdam Flight Information Region (FIR), standard arrival routes are flown until an IAF. These standard routes are known as Standard Terminal Arrival Routes (STARs).

After this STAR, during day-time hours, radar vectors are provided by ATC to perform the final sequencing and line up the aircraft with the runway at the ILS interception point. The radar vectoring reduces the situational awareness on the flight deck and the crew is not aware of the total remaining track miles to the runway. This information is critical to plan the remainder of the descent efficiently. Combined with tactical descent clearances from ATC, most often intermediate level segments are flown during approach. These level segments require a high thrust setting and during segments where the speed is low, flaps are extended as well. These extended flaps lead to high aerodynamic noise. Combined with the high thrust setting of the level segments, this contributes to high noise as experienced on the ground during these day-time approaches.

To reduce the amount of noise on communities near airports, numerous NAPs have been investigated throughout the years. An NAP already in use today is the CDA. Limitations on the runway throughput during CDAs, led to the development of other NAPs, such as the ACDA, the Three-Degree Decelerating 
Approach (TDDA) and the Free Degree Decelerating Approach (FDDA).

\section{II.A. Continuous Descent Approach}

When no other aircraft are airborne or approaching, an aircraft would fly a CDA during its approach, because it is the most natural way to perform an approach. The CDA reduces noise and fuel burn by keeping the aircraft higher and at lower thrust for a longer period than conventional step-down approaches, as shown in Fig. $1 .^{12}$

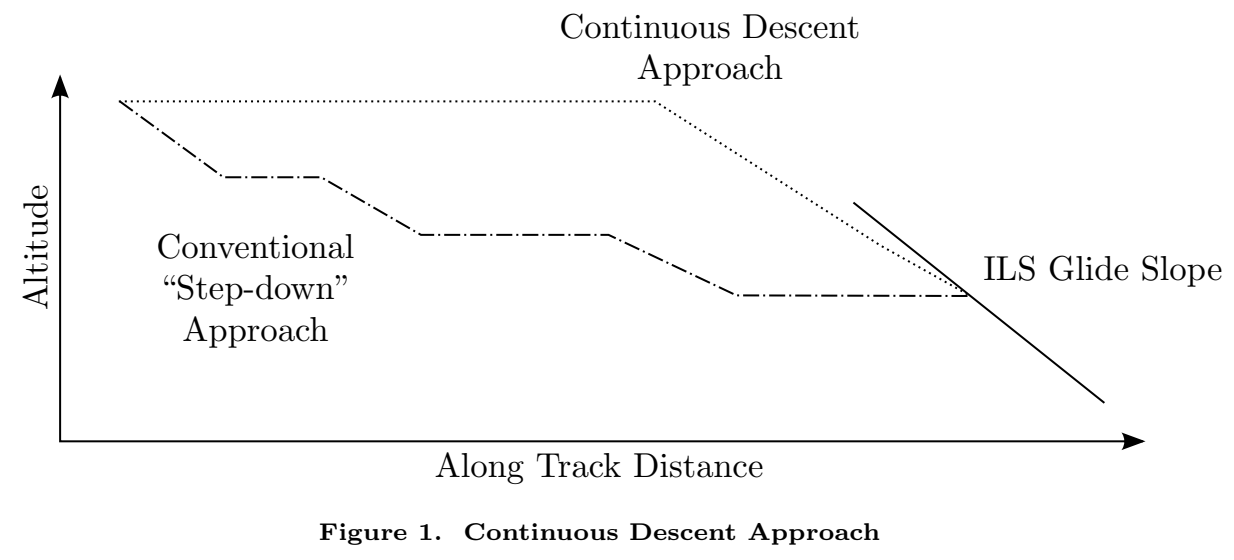

On Schiphol Airport, the CDA is already in use nowadays on runways 06 and 18R during night-time hours. When cleared for a CDA by ATC, the pilot is asked to make an optimum descent path with engines set to idle or near idle, from the IAF to the Final Approach Fix (FAF) at 2,000 ft above ground level. ${ }^{13}$ In most modern aircraft, this idle-thrust path is computed by the FMS.

Due to differences in aircraft performance between different aircraft types, difference in pilot behavior and due to changing wind conditions, resulting uncertainties in approach time predictions required that the separation distances between approaching aircraft had to be increased substantially. The landing interval was increased to 4 minutes. During day-time operations, the landing interval can be as low as 1.8 minutes.

\section{II.B. Advanced Continuous Descent Approach}

During CDAs, the differences in aircraft performance lead to a large dispersion in aircraft trajectories. To overcome this problem, the ACDA was developed. ${ }^{3}$ During an ACDA, the FMS is used to plan the trajectory and later on guide the aircraft during the execution of the ACDA such that it will meet the RTA constraint at the runway threshold, as given by ATC. A full 4D guidance during ACDA is therefore required. The FMS has to calculate the top of descent taking into account the actual and forecasted wind conditions and the aircraft's performance data. This full $4 \mathrm{D}$ guidance makes it possible for trajectory-predictors on the Air Traffic Management (ATM) side to predict the flight trajectory of the aircraft more accurately.

The FMS performs a backward calculation from the ILS intercept point to the top of descent, such that an idle descent is performed from top of descent to the ILS intercept point. The foreseen speeds depend on aircraft configuration and respective performance data. So the exact timing of the configuration change points has to be taken into account in the calculations, in order to meet the $4 \mathrm{D}$ trajectory requirements. Fig. 2 shows such an ACDA.

During the execution of an ACDA, deviation of the planned trajectory can occur, if the performance data and/or weather forecast data are not precise enough. These inaccuracies are compensated in the FMS by an earlier configuration setting to mitigate a positive altitude error. A negative altitude error is compensated by the introduction of a less steep segment and a small thrust increase to still meet the time constraint at the ILS interception point.

\section{II.C. Three-Degree Decelerating Approach}

The TDDA uses Area Navigation (RNAV) technology to perform the approach. During the TDDA, a curved or straight approach path at a $3^{\circ}$ angle is created from any point using RNAV technology. ${ }^{4}$ With 


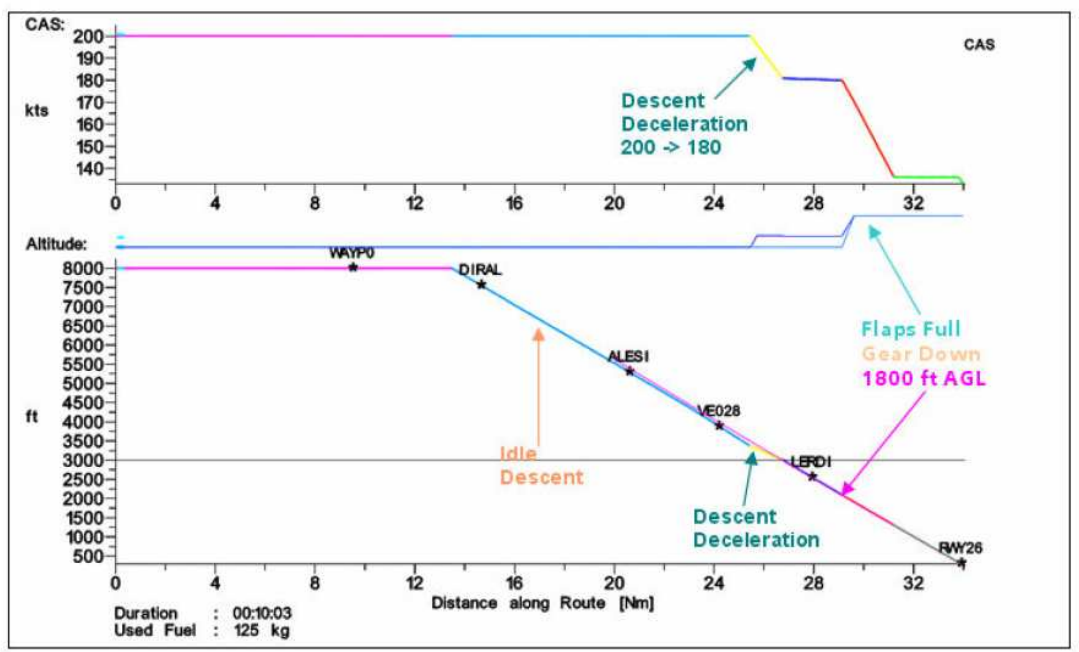

Figure 2. Advanced Continuous Descent Approach ${ }^{3}$

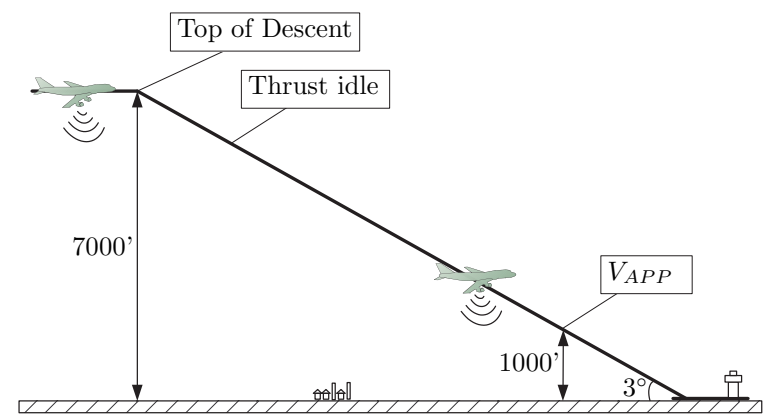

Figure 3. The Three-Degree Decelerating Approach ${ }^{7}$

an airspeed of $250 \mathrm{KIAS}$, the aircraft intercepts the ILS at e.g., 7,000 ft Above Ground Level (AGL) and starts its descent. At a predetermined altitude, the aircraft cuts back the thrust to idle and descends down to the reference altitude $h_{\text {ref }}$ at 1,000 ft above ground level. At this point, the aircraft should be fully configured for a stabilized approach with a constant speed, attitude and power setting. Fig. 3 gives an overview of this procedure.

The TDDA has intrinsically the same problem as the CDA. That is, differences in aircraft performance and uncertainties in wind conditions lead to the need to increase the separation between aircrafts. As a result, the runway capacity decreases. A suggested solution to this problem is to leave the task of separation completely to the pilot, by means of self-spacing. ${ }^{5}$ Information from the lead aircraft is obtained via Automatic Dependent Surveillance-Broadcast (ADS-B). This information is then used by a newly designed FMS algorithm to optimize a flap schedule.

Experiments done with this algorithm led to some comments regarding the continuously changing speeds at which the pilot should switch to the next flap setting. It turned out that these changing flap speeds could be disorderly and confusing to pilots, since these speeds can be different for each approach. This increased pilot workload. Another disadvantage occurred when the flaps were extended at higher speeds, as this may introduce problems with flap wear and passenger comfort. ${ }^{10}$

\section{II.D. Free-Degree Decelerating Approach}

To overcome the problem with changing flap speeds, a concept for a new type of CDA was developed, the FDDA. ${ }^{10}$ As opposed to the TDDA, the FDDA features constant flap speeds, which means that the speeds at which the next flap setting is selected are fixed during approach. In order to be able to control the approach time, the aircraft's flight-path angle is introduced as a control variable for the FDDA. Fig. 4 gives an example of an FDDA for a Boeing B747-200 model. ${ }^{10}$

The procedure for the FDDA is as follows; the thrust cutback altitude is set at 7,000 ft above ground level, where the speed is 250 KIAS. The goal is to arrive at $1,000 \mathrm{ft}$ above ground level with 


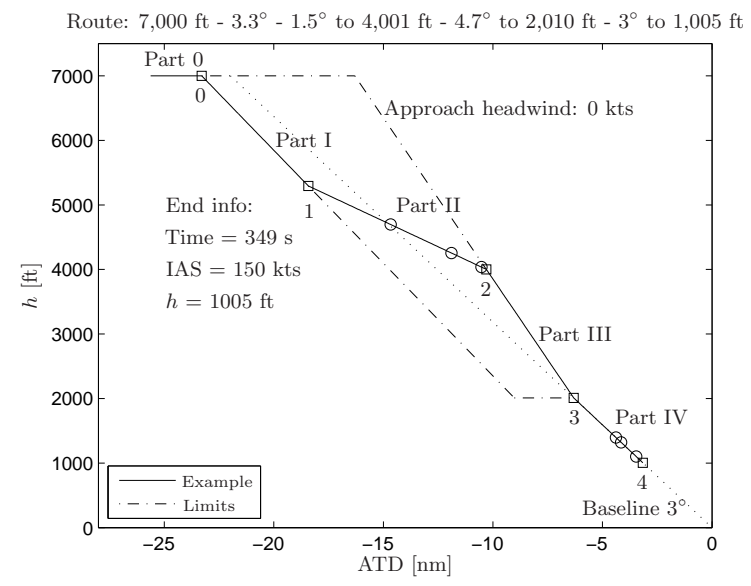

Figure 4. Example of an FDDA approach including two limit paths ${ }^{10}$

a final approach speed $\left(V_{a p p}\right)$ of 150 KIAS. The pilot receives an RTA from ATC, and with current wind predictions, the FDDA algorithm determines the approach path. The algorithm is defined with the following segments:

Part 0 A motored segment with 250 KIAS at 7,000 ft above ground level to the start of the descent.

Part I An idle thrust descent with constant Indicated Airspeed (IAS) and constant aerodynamic flightpath angle $\left(\gamma_{a}\right)$.

Part II An idle thrust decelerating segment of which the start altitude and flight-path angle may vary. Deceleration is achieved by flying with idle thrust while maintaining a constant kinematic flightpath angle $\left(\gamma_{k}\right)$ until the speed for Part III has been reached.

Part III An idle thrust segment with constant IAS and constant $\gamma_{a}$ until the $3^{\circ}$ glide slope of a standard ILS approach is intercepted from above at approximately $2,000 \mathrm{ft}$ above ground level.

Part IV An idle thrust decelerating segment along the $3^{\circ}$ glide slope from the intercept point until $V_{a p p}$ is reached at 1,000 $\mathrm{ft}$ above ground level.

In Fig. 4, two extreme paths are plotted (dashed lines) as well. One is the slowest path possible, which is the highest 'limit' line in the figure. For this path, Part I is not executed and Part II is executed level at 7,000 ft above ground level. The other 'limit' line is the fastest path possible. A characteristic for this path is that it has a very short third part (Part III).

\section{Variable Flight-Path-Angle Approach}

The current mode of operation of ATC is tactical and sector specific. Controllers work to meet speed, altitude and spacing requirements as the aircraft is passed onto the next sector. The resulting tactical clearances make it difficult to fly the efficient trajectory computed by the FMS of the aircraft. From the pilot's trajectory planning point of view, these clearances may appear excessive and uncoordinated. ${ }^{11}$

The FMS in current "glass" cockpit aircraft, permit aircraft to fly a prespecified sequence of trajectory segments with speed and altitude crossing restrictions accurately and efficiently. These work well when no additional constraints or lateral path changes are imposed by ATC. However, when new constraints must be imposed, current FMSs require significant pilot input on the CDU of the FMS to allow them to meet these constraints. In some cases, the FMS is not functionally capable of incorporating the new constraints, due to differences in trajectory generation techniques between ATC and FMS systems. In that case, pilots usually have to disconnect the LNAV and VNAV FMS functions and revert to more tactical autopilot modes.

\section{III.A. Concept}

To avoid these problems, a new approach procedure is proposed, that allows different pilot input to adapt the trajectory calculated by the FMS. To achieve this, a Vertical Situation Display (VSD) is used to 
plan the approach trajectory before the pilot enters the Terminal Maneuvering Area (TMA), instead of pilot input on the CDU. The involvement of the pilot in the planning of the approach procedure is also believed to increase situational awareness for the pilot. During the planning phase, the pilot can adapt an intermediate waypoint to create two segments with different flight-path angle. The cockpit devices necessary to allow this waypoint adaptation, are discussed in Section IV.

\section{III.B. Constraints}

Some constraints will be applied to the new procedure. First, the path will only be free in vertical direction. This means that the lateral path will be fixed for the entire procedure. The vertical path is free between the top of descent and the ILS interception point. This freedom will consist of two segments with variable flight-path angle. Another constraint applied to the vertical path, is that no level segments are allowed from the top of descent onwards, so the aircraft keeps descending continuously. Also, the aircraft is not allowed to accelerate during descent, so $V_{I A S} \leq 0$.

Furthermore, the flap schedule will be fixed for the approach procedure. Another constraint is that the ILS will be intercepted at 2,000 ft. From that point onwards, the aircraft must follow a normal ILS approach, with the aircraft established and in full landing configuration at 1,000 ft above ground level.

Because the flight-path angle is the control variable of the approach procedure, the procedure is called the Variable Flight-path angle Approach (VFA). To limit the amount of flight-path angle changes during descent, and thus limit the amount of pilot actions during the execution of the procedure, some additional constraints are introduced. One segment of constant flight-path angle has a minimum length of 5 NM. The last change in flight-path angle might not occur after 15 NM from the runway. This is approximately $8 \mathrm{NM}$ before the ILS intercept point.

\section{III.C. Execution}

After the pilot has selected the desired approach, the vertical path of the approach can be flown with the Flight-Path Angle (FPA) mode of the Mode Control Panel (MCP). This is an autopilot mode which keeps the aircraft on a constant kinematic flight-path angle $\gamma_{k}$. The pilot can adjust the desired flight-path angle with a knob on the MCP with an accuracy of $0.1^{\circ}$ and then the autopilot will guide the aircraft along this flight-path angle, independent of wind conditions. Airbus delivers this mode on all A320, A330, A340 and A380 aircraft. Boeing has introduced this mode on the B777, while also the upcoming B787 and B747-8 will have this autopilot mode.

To minimize the noise impact and reduce the emissions of greenhouse gasses, the VFA is flown with idle thrust settings for as long as possible. The thrust-cutback point is determined by a backwards calculation of the path after the vertical path is set by the pilot. The thrust is kept in idle mode, until the maximum speed of $250 \mathrm{KIAS}$ is reached by backwards calculation. This is the maximum speed inside Schiphol's TMA. ${ }^{14}$ The point at which this maximum speed is reached, is the thrust-cutback point.

The Autothrottle (A/T) can be set to Constant Speed Mode (SPD) at 250 KIAS at the beginning of the approach procedure. When the thrust-cutback point is reached, the pilot disconnects the A/T and moves the throttle-levers to idle, which can be maintained until the stabilization point at 1,000 $\mathrm{ft}$ above ground level. At that point, thrust is reapplied and the approach continuous with constant approach speed $V_{\text {app }}$.

\section{III.D. Offline simulations}

To investigate the feasibility of the VFA and to determine what the fastest and slowest approach would be by varying the flight-path angles, fast-time simulations were performed in MATLAB. These simulations were performed with a point-mass model of the aircraft and the equations of motion for this point-mass model are derived from Fig. 5.

\section{III.D.1. Equations of motion}

Assuming that the thrust vector is in-line with the velocity vector $\left(\alpha_{T} \approx 0\right)$, and assuming no wind, the symmetric equations of motion in the aerodynamic reference frame $\mathcal{F}_{a}$ are as given in Eq. (1) and Eq. (2). ${ }^{15}$

$$
\begin{aligned}
& \Sigma F_{x_{a}}=T-D+m g \sin \gamma_{a}=m \frac{d^{2} x}{d t^{2}} \\
& \Sigma F_{z_{a}}=-L+m g \cos \gamma_{a}=m \frac{d^{2} z}{d t^{2}}=m V_{a} \dot{\gamma}_{a}
\end{aligned}
$$




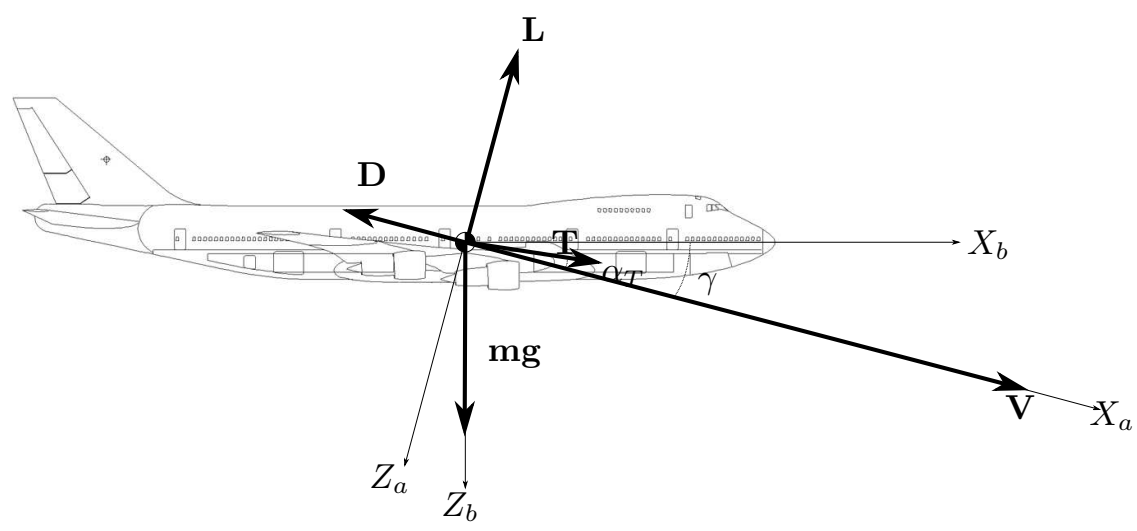

Figure 5. Force diagram of the aircraft

In these equations, $F$ is the total force and the $x$ and $z$ subscripts indicate the direction in the reference frame. $T$ is the thrust, $D$ the drag, $L$ the lift, $m$ the mass, $g$ the gravitational acceleration and $V$ the velocity. $\gamma_{a}$ is the aerodynamic flight-path angle and is assumed positive downwards. $x$ and $z$ indicate the position in the reference frame. For the point-mass model, the values of lift and drag in these equations are given by Eq. (3) and Eq. (4),

$$
\begin{aligned}
D & =C_{D} \frac{1}{2} \rho V^{2} S \\
L & =C_{L} \frac{1}{2} \rho V^{2} S
\end{aligned}
$$

In these equations, $C_{D}$ is the drag coefficient, $C_{L}$ the lift coefficient, $\rho$ the air density and $S$ the wing area. During the simulations, flight-path angle changes are assumed to occur instantaneous. This means that $\Sigma F_{z_{a}}=0$ and $\Sigma F_{x_{a}}=m \cdot a$, where $a$ is the acceleration. Eq. (1) and Eq. (2) can then be rewritten to Eq. (5) and Eq. (6). In these equations, $W=m \cdot g$.

$$
\begin{gathered}
a=g\left(\frac{T-D}{W}+\sin \gamma_{a}\right) \\
C_{L}=\frac{2 m g \cos \gamma_{a}}{\rho V^{2} S}
\end{gathered}
$$

\section{III.D.2. Boeing B747-200 model}

A point-mass model of a Boeing B747-200 was used for the offline simulations. For these point-mass model calculations, values of $C_{L}$ and $C_{D}$ were necessary. $C_{L}$ can be easily calculated with Eq. (6), and for the determination of $C_{D}$ values, use was made of the GARTEUR REconfigurable COntrol for Vehicle Emergency Return (RECOVER) aircraft simulation benchmark. ${ }^{16}$

This benchmark was developed to demonstrate, both offline and in real-time (piloted) simulation, the performance and viability of newly designed fault tolerant flight control algorithms. The software package, which is based on the Delft University Aircraft Simulation and Analysis Tool (DASMAT) ${ }^{17}$ is equipped with several simulation and analysis tools, all centered around a generic non-linear aircraft model for six-degrees-of-freedom non-linear aircraft simulations.

\section{III.D.3. Energy equations}

The validity of the path flown by the aircraft was tested by considering the total energy $E$, which is composed of the potential and kinetic energy, according to Eq. (7),

$$
E=m g h+\frac{1}{2} m V^{2}
$$

In this equation, $h$ is the geometric altitude. The trajectory that the aircraft follows, commands a total energy rate implicitly, $\dot{E}_{c m d}$, as given in Eq. (8). ${ }^{18}$

$$
\dot{E}_{c m d}=V W\left(\sin \gamma_{a}+\frac{\dot{V}}{g}\right)
$$


The total energy rate that can be attained by the aircraft when it is flying idle, can be calculated with Eq. (9).

$$
\dot{E}_{a / c}=V\left(T_{i d l e}-D\right)
$$

If the commanded energy rate is higher than the energy rate the aircraft can attain, the path that is commanded is not a path the aircraft is capable of flying, without accelerating and thus violating the VFA constraint that the aircraft is not allowed to accelerate. By defining the energy rate demand $\hat{E}$ as in Eq. (10), it can be stated that $\hat{E}$ must be smaller than 1 at every instant of the descent in order to be a descent that meets the VFA constraints, so $\hat{E} \leq 1$.

$$
\hat{E}=\frac{\dot{E}_{c m d}}{\dot{E}_{a / c}}=\frac{W\left(\sin \gamma+\frac{a}{g}\right)}{T_{i d l e}-D}
$$

\section{III.D.4. Trajectory calculations}

The actual simulations were performed by backward calculation of the trajectory. The vertical profile is defined by pilot input and predefined segments, which will be explained in Section IV. The simulation starts at the stabilization point at 1,000 ft. The landing reference speed $V_{\text {ref }}$ of a B747-200 in zero-wind conditions is $150 \mathrm{KIAS}$, therefore the speed at the stabilization point is chosen to be 150 KIAS. From here, the path calculations are performed assuming an idle-thrust $T_{i d l e}$ setting of $0 \mathrm{~N}$. In reality, an idle thrust setting of $5-10 \%$ of the maximum thrust $T_{\max }$ would be more realistic, but because the aircraft dynamics (Section V.B.3 used in the experiment assumes an idle thrust setting of 0 N, this setting is also used for the offline simulations. The flap schedule used for the calculations is given in Table 1.

Table 1. Flap speeds used for the simulations

\begin{tabular}{ccc}
\hline \hline Flap setting & Gear & IAS [kts] \\
\hline UP & UP & $235-250$ \\
5 & UP & $200-235$ \\
10 & UP & $180-200$ \\
10 & DOWN & $175-180$ \\
25 & DOWN & $150-175$ \\
\hline
\end{tabular}

With the idle thrust setting, the acceleration of the aircraft can be calculated with Eq. (5). This can then be used to calculate the speed of the aircraft at the next simulation step. If at any point during the simulation, the IAS is smaller than the IAS of the previous simulation step, which would mean an acceleration during the execution of the path, the VFA constraint of being a decelerating approach is violated and the path is marked as being an invalid solution.

The idle thrust setting for the calculations is maintained until the maximum TMA speed is reached, which is 250 KIAS. From that point onwards, the thrust setting is variable based on speed and vertical path. It can be calculated with Eq. (11).

$$
T=\left(\frac{a}{g}-\sin \gamma_{a}\right) W+D
$$

In this equation, $a$ is again the acceleration, which is small in this case, because it is only dependent on differences in True Airspeed (TAS) with altitude $h$ for the same constant speed of 250 KIAS. When an aircraft is descending, it decelerates slightly in TAS when keeping a constant IAS. If the thrust is known, the value of $a$ can be calculated with Eq. (17), by setting $\frac{d}{d t}\left(V_{E A S}\right)=0$.

\section{III.D.5. Grid setup}

The first variable that must be investigated is the Top Of Descent (TOD) of the approach. The top of descent furthest from the runway is taken as $60 \mathrm{NM}$. The top of descent is then decreased with 5 NM each time, until the minimum top of descent of $20 \mathrm{NM}$ is reached. This then gives a range of nine different top of descents, for which the fastest and slowest approach can be investigated. 
Now, for every top of descent, a grid is set up with points at an interval of $250 \mathrm{ft}$ in height and $1 \mathrm{NM}$ in Distance-To-Go (DTG) to obtain a reasonable number of data points. The grid is set up such that it complies with the constraints that the last change is 15 NM before the runway, a flight-path angle change spans at least $5 \mathrm{NM}$ and there are no level segments. A sample grid can be found in Fig. 6. This is the grid for a top of descent of $50 \mathrm{NM}$.

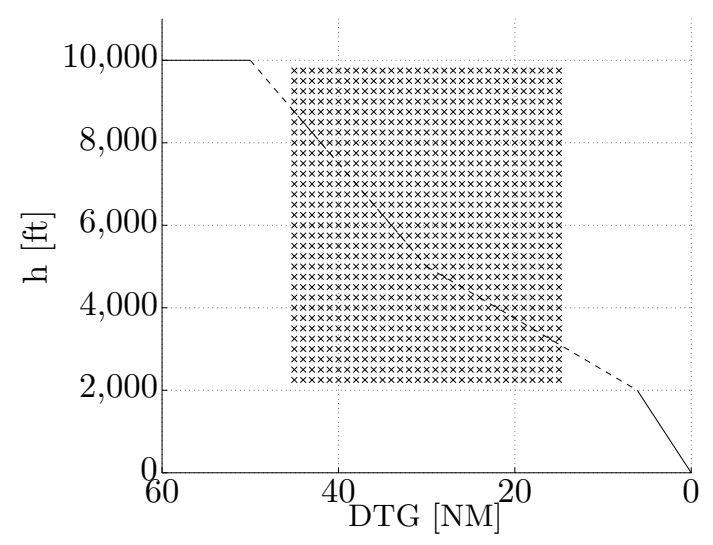

Figure 6. Grid setup for a top of descent of 50 NM

For each point of the grid the accompanying path is calculated. For this research, the path is divided into two segments with different flight-path angle between the top of descent and the ILS intercept point. An example path is plotted with the dashed line in Fig. 6. This path has an intermediate waypoint at $5,000 \mathrm{ft}$ and $30 \mathrm{NM}$. To compare the different top of descents, the fastest and slowest approach for that particular top of descent are given in Table 2. These fastest and slowest approaches were obtained by calculating the approach time of the path accompanying every point in the grid. Then, the fastest and slowest approaches could simply be obtained by selecting the minimum and maximum values of the gathered approach times for each top of descent.

Table 2. Fastest and slowest approach for variable top of descent

\begin{tabular}{ccc}
\hline \hline TOD $[\mathrm{NM}]$ & Fastest $[\mathrm{s}]$ & Slowest $[\mathrm{s}]$ \\
\hline 60 & 905 & 948 \\
55 & 905 & 948 \\
50 & 905 & 948 \\
45 & 905 & 948 \\
40 & 905 & 948 \\
35 & 902 & 948 \\
30 & 916 & 947 \\
25 & 935 & 946 \\
20 & - & - \\
\hline \hline
\end{tabular}

As seen in this table, the top of descent at $20 \mathrm{NM}$ from the runway does not give a trajectory that meets the VFA constraints. For the top of descent at 25 and $30 \mathrm{NM}$, the control space is limited. For all the other top of descents, the control space is more or less the same. Apparently, the slowest and fastest trajectories for these top of descents are approximately the same. Therefore, attention is given to the number of valid paths that a top of descent gives. Fig. 7 gives the valid solutions for a top of descent of 55, 50 and $45 \mathrm{NM}$.

As seen in these figures, a top of descent of $45 \mathrm{NM}$, gives significantly fewer possible trajectories compared to 50 and $55 \mathrm{NM}$. Now, a trade-off needs to be made between the availability of valid trajectories, and the amount of planning time given to the pilot during the experiment. Because during the experiment each run will start at $65 \mathrm{NM}$ before the runway, the top of descent is set to $50 \mathrm{NM}$, which gives the pilot 15 NM to plan his trajectory.

Now that the approach times are known for all the valid points of the grid, this can be used to make 


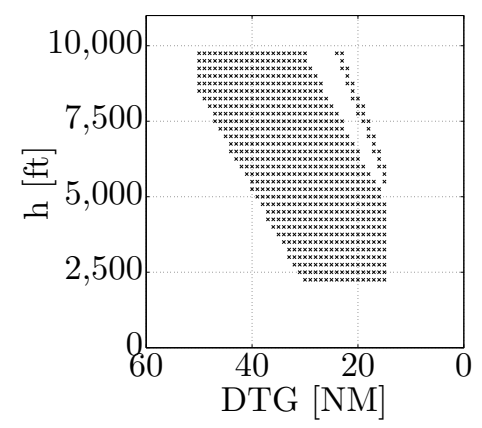

(a) TOD $55 \mathrm{NM}$

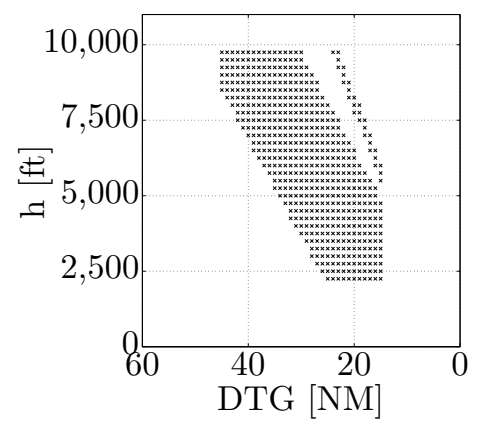

(b) TOD $50 \mathrm{NM}$

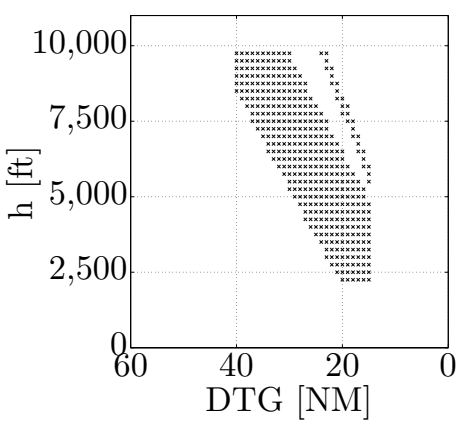

(c) TOD $45 \mathrm{NM}$

Figure 7. Valid solutions for different top of descents

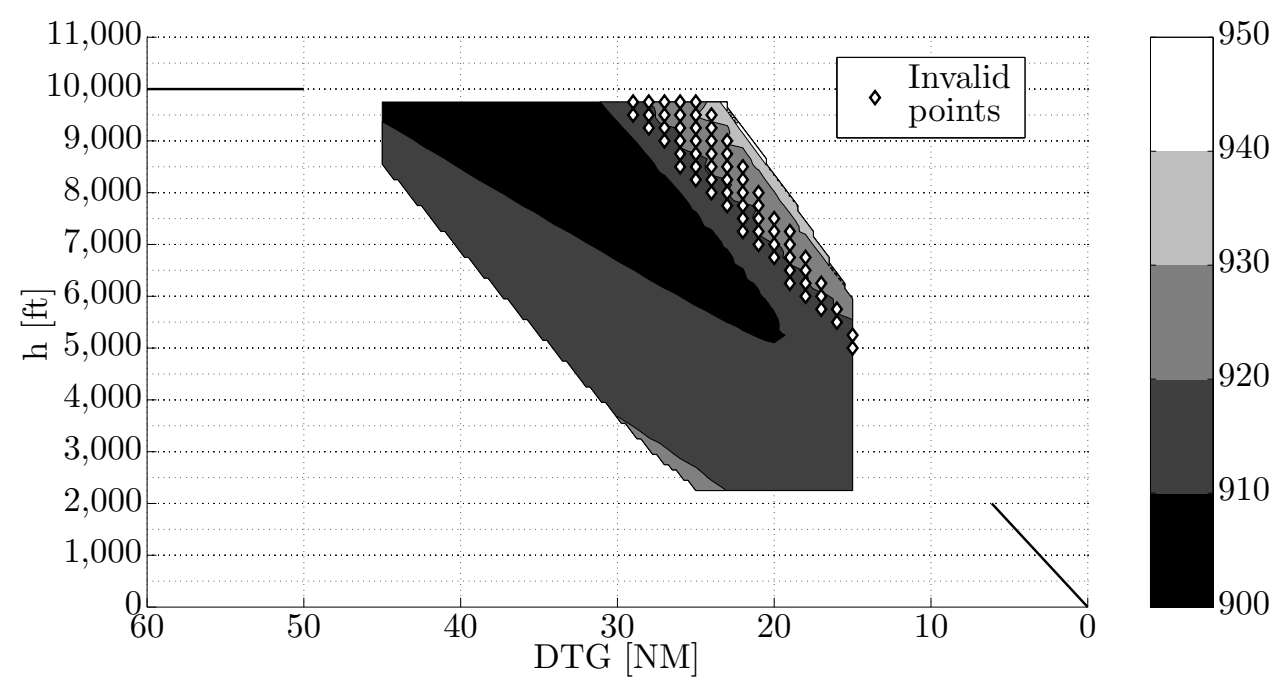

Figure 8. Contour plot for a top of descent of 50 NM

a contour plot of these approach times. This contour plot can be found in Fig. 8 .

III.D.6. Approach time contour plot analysis

In order to be able to explain the shape of the contour plot and to investigate the regions of invalid points in Fig. 8, the maximum glide angle for which the aircraft will not accelerate in IAS needs to be calculated.

This maximum angle for which the aircraft can glide without accelerating in IAS can be deduced from the equations of motion and a simplified relationship between IAS and TAS. When assuming an incompressible isentropic flow, which is a valid assumption for low subsonic speeds, Calibrated Airspeed (CAS) can be assumed to be equal to Equivalent Airspeed (EAS). ${ }^{15}$ Instrument error is also neglected, which means that CAS (and thus EAS) is equal to IAS. The relation between TAS and EAS (and thus IAS) is given in Eq. (12).

$$
\rho V_{T A S}^{2}=\rho_{0} V_{E A S}^{2}
$$

In this equation, $\rho_{0}$ is the sea-level air density in standard atmosphere. Taking the time derivative of this equation leads to Eq. (13).

$$
V_{T A S}^{2} \frac{d \rho}{d t}+2 \rho \cdot V_{T A S} \cdot \frac{d}{d t}\left(V_{T A S}\right)=2 \rho_{0} \cdot V_{E A S} \cdot \frac{d}{d t}\left(V_{E A S}\right)
$$

The equation to calculate air density $\rho$ is given in Eq. (14). The time derivative of the air density $\frac{d \rho}{d t}$ is given in Eq. (15). The time derivative of the TAS is equal to the acceleration of the aircraft and was already given in Eq. (5). 


$$
\begin{gathered}
\rho=\rho_{0}\left(1+\frac{H \lambda}{T_{0}}\right)^{-\left(\frac{g_{0}}{R \lambda}+1\right)} \\
\frac{d \rho}{d t}=-\left(\frac{g_{0}}{R \lambda}+1\right) \rho_{0}\left(1+\frac{H \lambda}{T_{0}}\right)^{-\left(\frac{g_{0}}{R \lambda}+2\right)} \frac{d H}{d t} \frac{\lambda}{T_{0}}
\end{gathered}
$$

In these equations, $g_{0}$ is the gravitational acceleration at sea level in standard atmosphere, $R$ is the specific gas constant of air, $\lambda$ is the lapse rate of air in the troposphere, $T_{0}$ the sea level temperature and $H$ is the geopotential altitude. Assuming the time derivative of the geopotential altitude equal to the time derivative of the geometrical altitude, this time derivative can be calculated with Eq. (16). $\frac{d H}{d t}$ is negative for positive $\gamma$, due to the fact that $\gamma$ is assumed positive during descent (see Fig. 5).

$$
\frac{d H}{d t}=-V_{T A S} \sin \gamma_{a}=-V_{E A S} \sqrt{\frac{\rho_{0}}{\rho}} \sin \gamma_{a}
$$

Rearranging Eq. (13), and substituting Eq. (5), Eq. (15) and Eq. (16) leads to Eq. (17).

$$
\begin{aligned}
\frac{d}{d t}\left(V_{E A S}\right)= & \left(\frac{g_{0}}{R \lambda}+1\right)\left(1+\frac{H \lambda}{T_{0}}\right)^{-\left(\frac{g_{0}}{R \lambda}+2\right)} V_{E A S}^{2}\left(\frac{\rho_{0}}{\rho}\right)^{\frac{3}{2}} \frac{\lambda}{2 T_{0}} \sin \gamma \\
& +\sqrt{\frac{\rho}{\rho_{0}}} g\left(\frac{T-D}{W}+\sin \gamma\right)
\end{aligned}
$$

To calculate the maximum angle for which the aircraft will glide without accelerating in IAS, Eq. (17) can be set to zero. Separating terms with $\gamma$ from terms without $\gamma$ gives Eq. (18). Then, the resulting angle can be calculated with Eq. (19).

$$
\begin{aligned}
& \sin \left(\gamma_{\max }\right) {\left[\sqrt{\frac{\rho}{\rho_{0}}} g+\left(\frac{g_{0}}{R \lambda}+1\right)\left(1+\frac{H \lambda}{T_{0}}\right)^{-\left(\frac{g_{0}}{R \lambda}+2\right)} V_{E A S}^{2}\left(\frac{\rho_{0}}{\rho}\right)^{\frac{3}{2}} \frac{\lambda}{2 T_{0}}\right] } \\
&=-\sqrt{\frac{\rho}{\rho_{0}}} g\left(\frac{T-D}{W}\right) \\
& \gamma_{\max }=\arcsin \left(\frac{-\sqrt{\frac{\rho}{\rho_{0}}} g\left(\frac{T-D}{W}\right)}{\sqrt{\frac{\rho}{\rho_{0}}} g+\left(\frac{g_{0}}{R \lambda}+1\right)\left(1+\frac{H \lambda}{T_{0}}\right)^{-\left(\frac{g_{0}}{R \lambda}+2\right)} V_{E A S}^{2}\left(\frac{\rho_{0}}{\rho}\right)^{\frac{3}{2}} \frac{\lambda}{2 T_{0}}}\right)
\end{aligned}
$$

Now that the maximum glide angle can be calculated, the grid of the contour plot is further refined for analysis. The top of descent is set again to $50 \mathrm{NM}$, but the step size of the grid is now decreased to $0.25 \mathrm{NM}$ and $100 \mathrm{ft}$. By refining the grid, the boundaries of the regions of invalid points become better visible.

The resulting contour plot can be found in Fig. 9. The horizontal and vertical boundaries of the contour plot are a direct result of the constraints given in Section III.A. That is, a flight-path angle change holds for at least $5 \mathrm{NM}$, no level segments are allowed and the latest change is no later than $15 \mathrm{NM}$ before the runway.

Through backwards calculation of the approach trajectory, it is known that the IAS at the ILS intercept point is 193 KIAS (2,000 ft). Therefore, the flap setting is Flaps 10 at that point with the gear up. For that speed, altitude and flap and gear setting, the maximum glide angle is calculated to be $\gamma_{\max }=4.48^{\circ}$ with Eq. (19). This angle is indicated with the dotted line in Fig. 9. Steeper descents violate the VFA constraint of $V_{I A S} \leq 0$ and therefore all points in region (1) are invalid solutions.

To investigate the influence of the Flaps 5 setting on the contour plot, $\gamma_{\max }$ is calculated for different altitudes and speeds, because the altitude at which the aircraft flies 200 KIAS is trajectory dependent. At $2,000 \mathrm{ft}$ and $200 \mathrm{KIAS}, \gamma_{\max }=4.50^{\circ}$. At $5,000 \mathrm{ft}$ and $200 \mathrm{KIAS}, \gamma_{\max }=4.48^{\circ}$. The dashed line in Fig. 9 gives the $\gamma_{\max }=4.50^{\circ}$ for Flaps 5. $\gamma_{\max }=4.48^{\circ}$ is the same as for Flaps 10 and was already given by the dotted line. Because $\gamma_{\max }$ for Flaps 5 is larger or equal to Flaps 10, this flap setting has no further influence on the shape of the contour, because all approaches that are steep enough to violate the VFA constraint of $V_{I A S} \leq 0$, already violated this constraint for Flaps 10.

To investigate why a point gives a valid or invalid solution in regions (2), (3) and (4), $\gamma_{\max }$ for Flaps 0 is also investigated. For $5,000 \mathrm{ft}$ and $235 \mathrm{KIAS}, \gamma_{\max }=3.12^{\circ}$. For $10,000 \mathrm{ft}$ and $235 \mathrm{KIAS}, \gamma_{\max }=3.09^{\circ}$. 


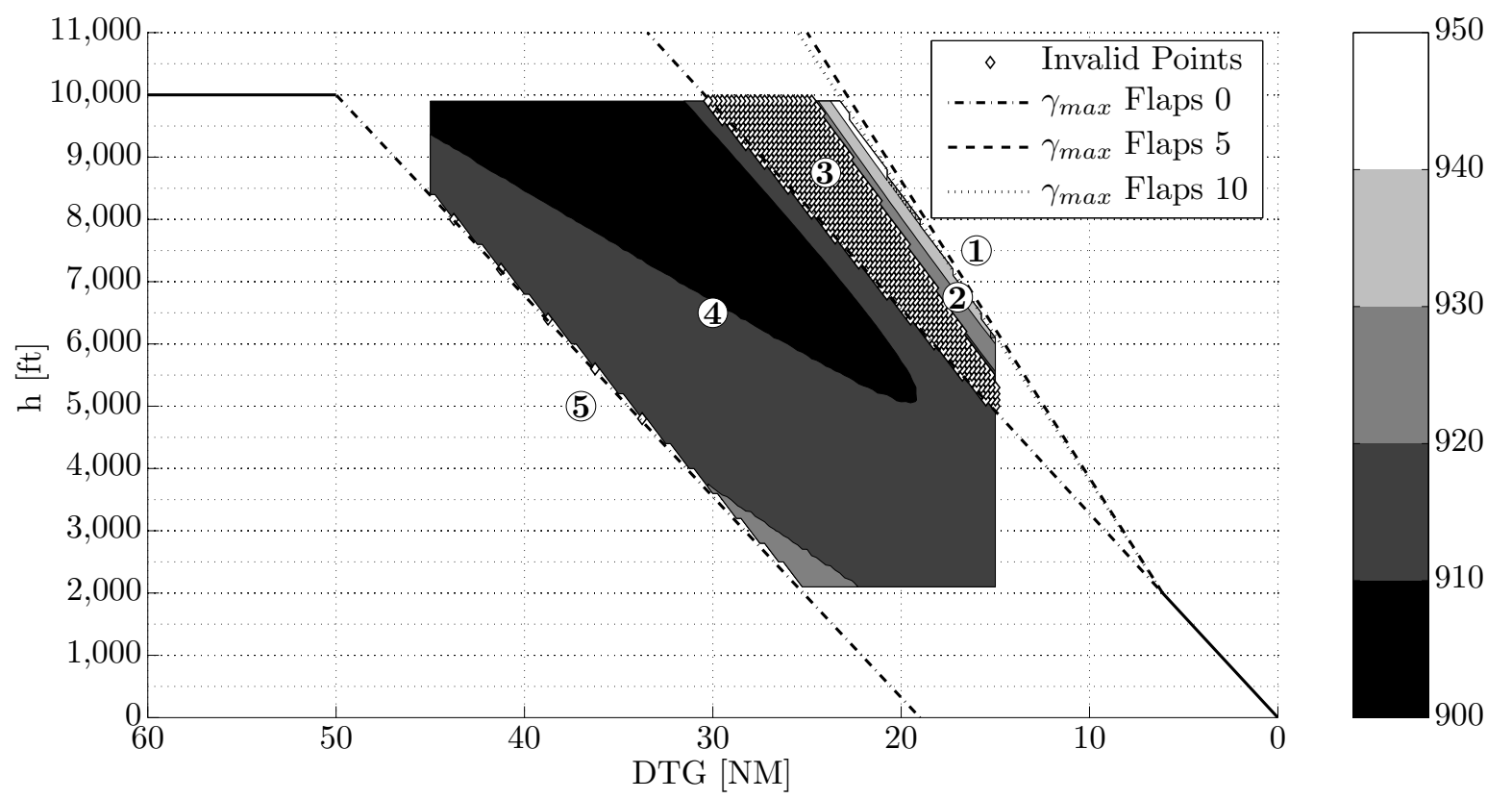

Figure 9. Analysis of time contour plot

So the dependence of $\gamma_{\max }$ on altitude is small. The dash-dotted line in the figure indicates $\gamma_{\max }=3.12^{\circ}$ for Flaps 0 . The reason why points in region (3) are invalid trajectories and in (2) valid, lies in the fact that the points in the last region result in a trajectory that has a second segment with a steep enough flight-path angle to maintain an IAS below 235 KIAS, and retain a flap setting of Flaps 5 as such. All points in region (3) have a segment from the selectable waypoint to the ILS intercept point, that is not steep enough to have an IAS below 235 KIAS for the whole segment. Region (4) only contains valid solutions, because the flight-path angles of both segments between top of descent and ILS interception point are both smaller than $\gamma_{\max }$ of all flap settings.

The differences between region (5) and (4) is that for the first region, the path from top of descent to the intermediate point is steeper than $\gamma_{\max }$ for Flaps 0 . This is also why the boundary between these two regions is parallel to the dash-dotted line. Because this first segment is too steep, the points in region (5) give invalid trajectories.

\section{Pilot Support Interface}

Because current FMSs require significant pilot input on the CDU to adapt the to-be-flown trajectory, a trajectory planning tool was developed to assist the pilot in establishing the correct VFA as well. This tool can be activated by changing from "MAP" to "PLN" mode on the Electronic Flight Instrument System (EFIS) control panel. The planning tool will then be displayed on the Vertical Situation Display (VSD).

\section{IV.A. Vertical Situation Display}

The VSD represents the vertical situation of the trajectory by a two-dimensional side-view of the trajectory. It is usually located underneath the Navigation Display (ND). In this way, a complete lateral and vertical view of the trajectory is presented to the pilot in one display.

This VSD can already be found in a variety of current "glass" cockpits. Boeing has this display optional on the B737-NG, ${ }^{19}$ and it will be delivered standard on the future Boeing 787 and Boeing 747-8.$^{20}$ An Airbus aircraft currently equipped with the VSD is the A380, while the future A350 will also be equipped with this display. ${ }^{21}$

When selecting the "PLN" mode instead of "MAP" mode on the EFIS control panel, the newly designed VSD display mode will look like Fig. 10(a). On the horizontal axis, the Distance-To-Go to the runway threshold is displayed. The aircraft symbol is indicated with a white triangle. This symbol will move along the path, while the rest of the display remains static. During normal operations, this is exactly the opposite. The aircraft remains static then, and the waypoints etc. move along the display. 
Also, the Along-Track-Distance is displayed during normal operations, instead of Distance-To-Go. The magenta contour around the intermediate waypoint indicates the range of possible approach solutions. The boundaries of this contour are determined by the VFA constraints and the maximum angles for constant IAS at the top of descent and ILS intercept point as given in Eq. (19). The dark contour boundary is equal to the maximum angle for Flaps 10, whereas the lighter contour is equal to the maximum angle for Flaps 5. Even when the suggested waypoint "WPT" lies within this contour, it is possible that at some point along the suggested path, the commanded energy rate is larger than the energy rate the aircraft can attain with its current flap and gear setting. The energy rate demand $\hat{E}$ of Eq. (10) is then larger than 1. The suggested path is not a valid solution in that case, and will be displayed in red to the pilot, instead of green for the valid solutions, as indicated in Fig. 10(b). When a solution is valid, the flight-path angles of the two segments will be displayed with amber labels.

After the pilot has selected his desired approach, the VSD can be set back to "MAP" mode. In MAP mode, the VSD will look like Fig. 10(c). The next waypoint is indicated in magenta, whereas all the other waypoints are white. For each waypoint the name, the height restriction and the flight-path angle that has to be flown in the segment following that waypoint is given. The point where the pilot has to disconnect the $\mathrm{A} / \mathrm{T}$ and start flying idle, is also indicated in the MAP mode with an amber line and the word "IDLE" above it.

Information that is always available in the VSD is the RTA and current time. The RTA given by ATC is displayed in the upper right corner of the display. and the current time in the upper left corner. Furthermore, when in PLN mode, the Estimated Time of Arrival (ETA) is indicated with a green label.

\section{IV.B. Primary Flight Display and Navigation Display}

The Primary Flight Display (PFD) used, is an adapted version of a standard Boeing 747 PFD, see Fig. 11(a). The flap indications given at (1) are the flap speeds according to the flap schedule given in Table 1. Current and next flap setting are indicated in green, whereas the gear down speed is indicated in amber. At (2), the current flap setting is dipslayed. Finally, at (3), an idle counter will be displayed. This counter starts 3 seconds before reaching the point where the pilot needs to start flying idle, so the pilot can time the thrust cutback point precisely.

The route with waypoints is indicated in the ND. The only cue added to the ND is the idle line, just as in the VSD. At that point the pilot needs to move the throttles to idle position. The ND can be found in Fig. 11(b).

\section{IV.C. Input method}

For the VFA, the pilot must be able to manipulate the location of the intermediate waypoint "WPT" within the contour. For this manipulation, it is assumed that the cockpit is equipped with a device that allows this manipulation. Boeing equips all its B777 models with a so-called Cursor Control Device (CCD). This is a touch sensitive panel with associated push button switches that are used to control cursor movement on the display, analogous to the mouse of a personal computer ${ }^{22}$ The new Boeing 787 and 747-8 will also have this device on board.

Airbus has introduced a so-called Keyboard and Cursor Control Unit (KCCU) on the A380. This unit combines a trackball, scroll wheel and a QWERTY keyboard into a single pilot input unit. This unit will also be implemented in the new A350. ${ }^{21}$

\section{IV.D. Algorithm}

The determination of the boundaries of the contour in the VSD and the path calculations during the planning phase can be done with FMS algorithms. In this research, algorithms were used based on Standard Aircraft Modelling Interface (SAMI). SAMI was developed by EUROCONTROL as a standard code-library to interface with their different performance models. The performance model which SAMI used for this research was a Base of Aircraft Data (BADA) Boeing 747-200 model. ${ }^{23,24}$ A possible output of SAMI is the descent rate of a constant-CAS profile. This can then be used to determine the flight-path angle for this constant-CAS profile. This in turn determines the boundaries of the contour as plotted in the VSD during the plan phase. 


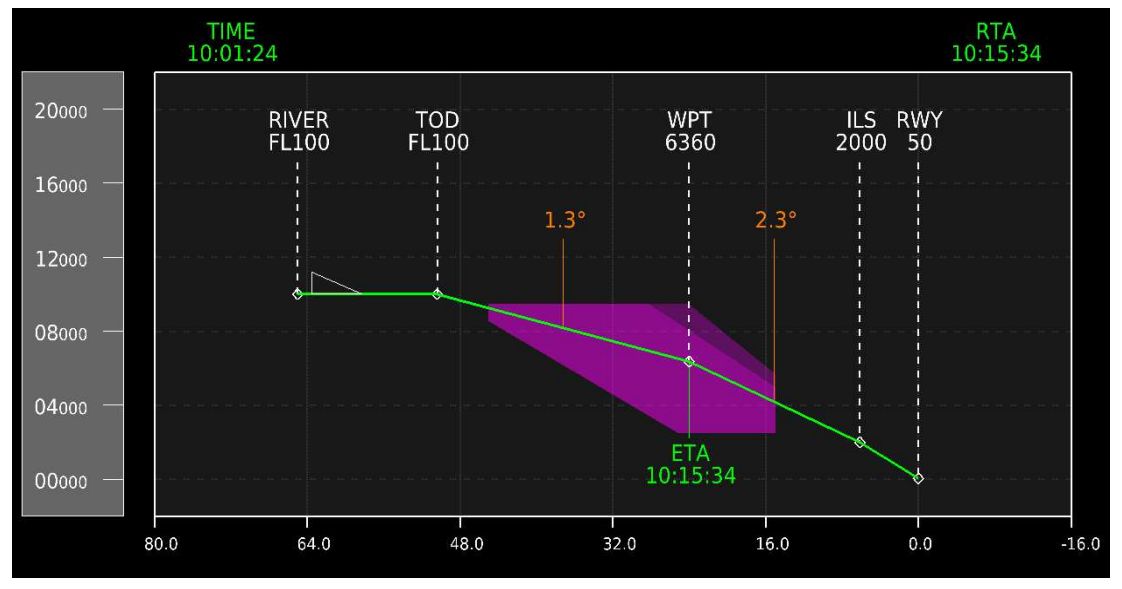

(a) PLN Mode with valid trajectory

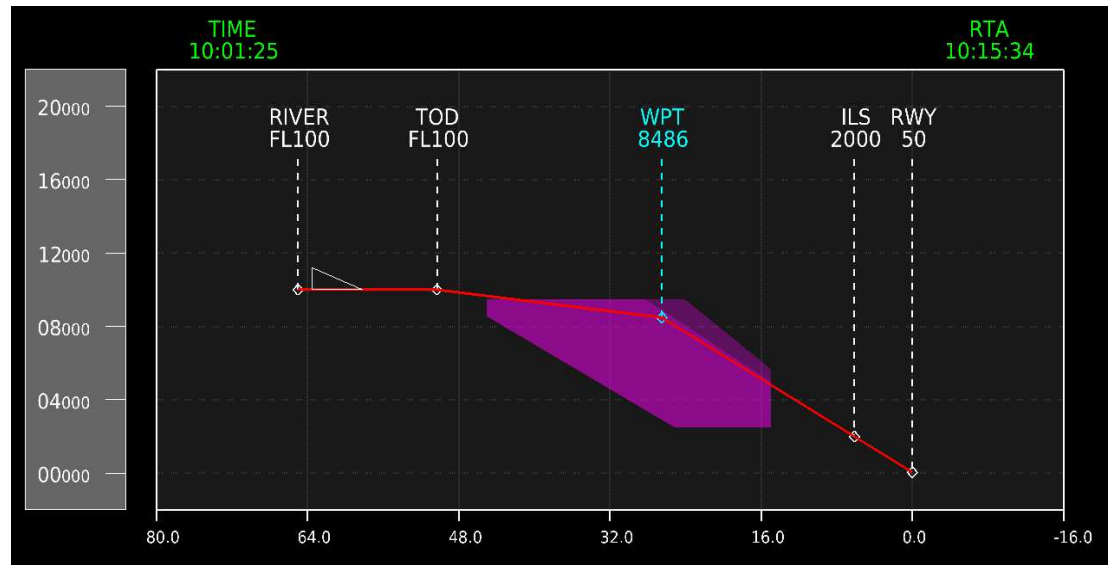

(b) PLN Mode with invalid trajectory

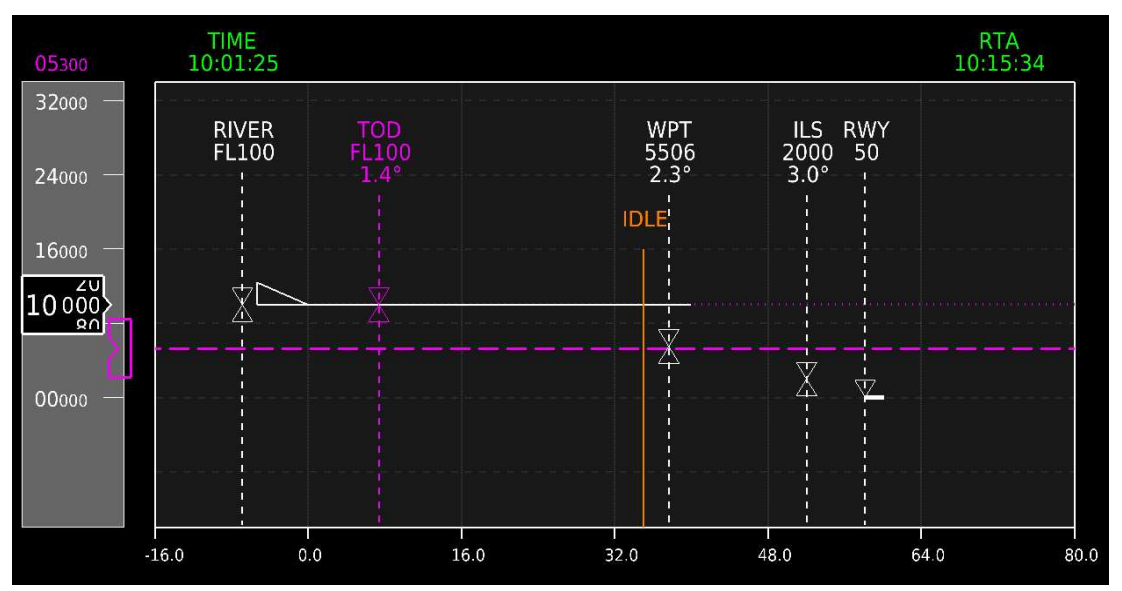

(c) MAP Mode

Figure 10. Vertical Situation Display (VSD) 


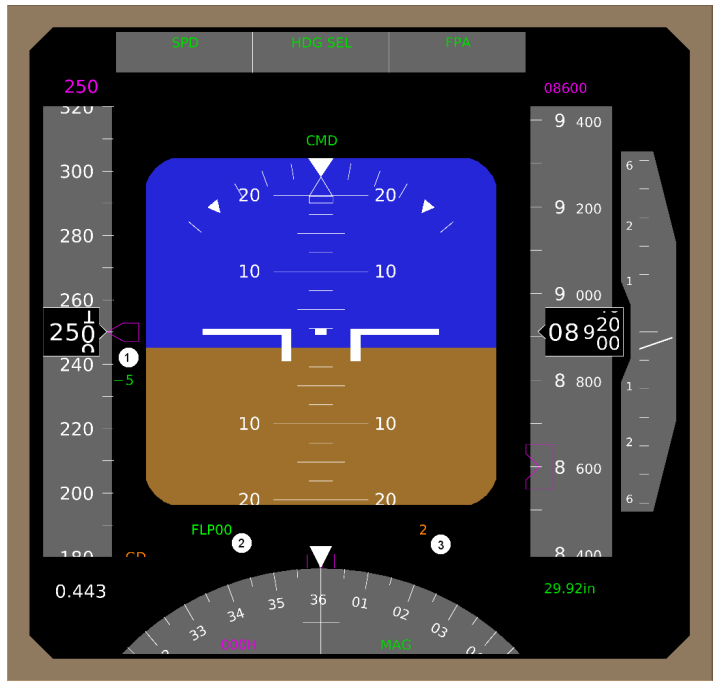

(a) PFD

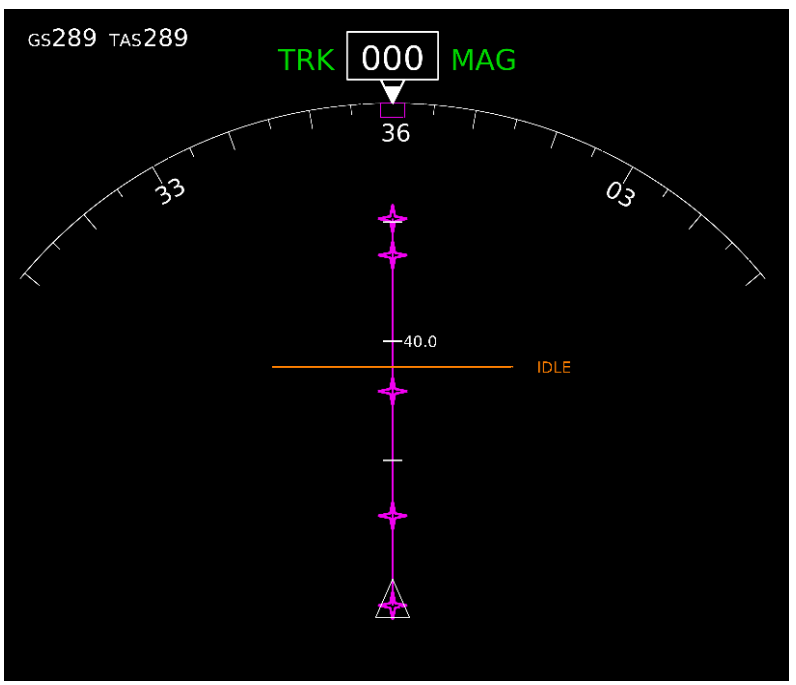

(b) ND

Figure 11. Primary Flight Display and Navigation Display

\section{Evaluation}

\section{V.A. Goal of the Experiment}

The goal of the experiment was to evaluate the VFA procedure and the accompanying pilot support interface described in Section IV subjectively. Also, pilot workload and performance will be measured during the experiment.

\section{V.B. Method}

\section{V.B.1. Subjects and Instructions}

The experiment involved two professional airline pilots and two research pilots. Both airline pilots have over 2,000 flying hours in a Boeing 737 NG. One of the research pilots has 350 flying hours in a Cessna Citation II, whereas the other research pilot has 700 flying hours in this aircraft. They both are also experienced in flying experiments with new displays in simulators.

For each run, the pilots were instructed to plan an appropriate approach trajectory in PLN Mode first, to match the ETA with the instructed RTA. When the pilot was satisfied with the selected trajectory, he was instructed to fly the approach without making any further adjustments to the trajectory. The pilots were instructed to follow the flap, gear and throttle schedule as close as possible, but deviations were allowed when pilots felt that they could not get the aircraft stabilized at 1,000 ft. Because there was no feedback about the current ETA during the execution of the approach, the pilots were instructed not to try to influence the ATA themselves, but rather just fly the selected approach trajectory as close to the instructed flap and gear schedule as possible.

\section{V.B.2. Apparatus}

For the experiment, the Human-Machine Interaction Laboratory (HMI-Lab) located at the faculty of Aerospace Engineering of Delft University of Technology was used. This laboratory consists of a fixedbase car simulator and a fixed-base aircraft simulator. Fig. 12 shows a picture of this laboratory, with the cockpit mock-up of the aircraft simulator displayed. Two displays can be found in this cockpit, the right display was used to display the PFD, while the left one was used to display the ND and VSD. A throttle quadrant is present in the lab, which was used by the pilots to control flaps, gear and throttle settings. The pilot could control the autopilot and display modes with the MCP and EFIS control panel respectively, located at the top of the cockpit mock-up.

\section{V.B.3. Simulation Environment}

For the dynamics of the aircraft, a linear model based on SAMI was used. For this experiment, the aircraft dynamics were again based on a BADA Boeing 747-200 model. ${ }^{23,24}$ One of the characteristics of 


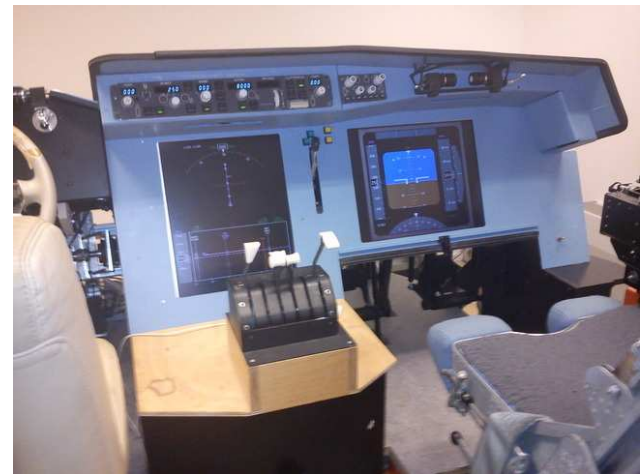

Figure 12. Human-Machine Interaction Laboratory (HMI-Lab) at Delft University of Technology (DUT)

this model is that idle thrust is assumed to be $0 \%$ of the maximum thrust. All approaches are flown in International Standard Atmosphere (ISA) conditions and wind conditions were absent during the whole experiment.

The simulation ran on DUECA/DUSIME ${ }^{25}$ which is a middle-ware layer and application framework that facilitates the development of real-time distributed processes, written in $\mathrm{C}++$. For this experiment, DUECA took care of the data-flow architecture between the four computers that were active during the execution of the experiment.

\section{V.B.4. Measurements}

During the experiment, aircraft state parameters and pilot input actions were logged. Also, the time was logged. This was used to determine the ATA, which could then be compared to the RTA.

After each run, the pilot was asked to fill in a NASA Task Load indeX (TLX) workload sheet. The NASA TLX provides an overall workload score based on weighted average of ratings on six sub-scales: mental, physical and temporal demands, performance, effort and frustration.

At the end of the experiment, the pilots were asked to fill in a questionnaire. This questionnaire consisted of a number of statements and a number of open questions or general comments. The intention of the questionnaire was to acquire improvement points for a future, larger experiment.

\section{V.B.5. Experiment Design}

Each subject performed five approaches of each approximately a quarter of an hour in duration. All these five runs were exactly the same straight-in approaches, starting with the aircraft trimmed at 250 KIAS and 10,000 ft. The fictitious starting time was 10:00:00 for each run. The only variable between the runs was the RTA.

The first two runs were used as training runs. Extensive explanation was given to the subjects during these runs. After that, three different scenarios were tested. These scenarios consisted of (1) a scenario with a late RTA of 10:16:01, (2) an intermediate RTA of 10:15:40 and (3) a fast approach with an RTA of 10:15:18.

The subjects were instructed as explained in Section V.B.1. The only addition to this, is that the Flaps 10 setting was recalculated at 12 NM before the runway. This was necessary, because small errors lead to a late or early Flaps 10 selection, which in turn lead to problems in getting the aircraft stabilized at 1,000 ft. These small errors originate from the fact that the trajectory is calculated with instantaneous path changes, while the pilots fly the path with more gradual path transitions. Most of the time, the necessary correction was in the order of one or two knots above or below the intended flap selection point at 200 KIAS.

\section{V.C. Results}

\section{V.C.1. Performance}

Fig. 13 gives the vertical profile of the solutions chosen by the subjects. For Scenarios 1 and 2, Subjects 1 and 4 chose the same solution. For Scenario 3, Subjects 2 and 4 chose the same solution.

As a measure for performance, the difference between ATA and RTA was measured. This difference is given in Table 3 for each subject and scenario. A positive number in this table indicates a late ATA, 


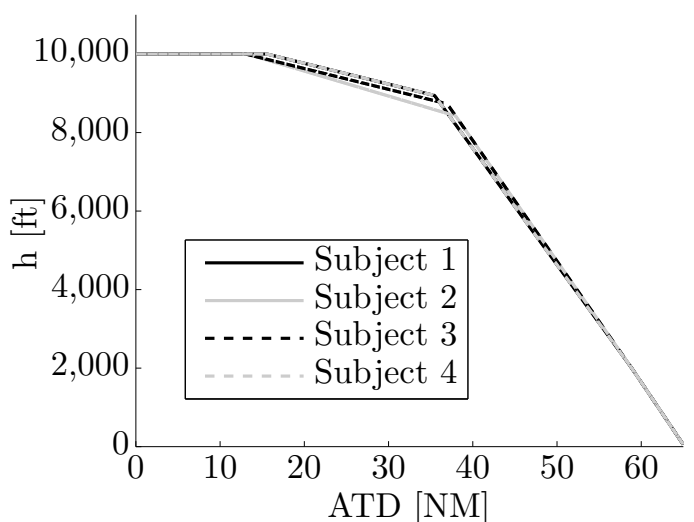

(a) Scenario 1

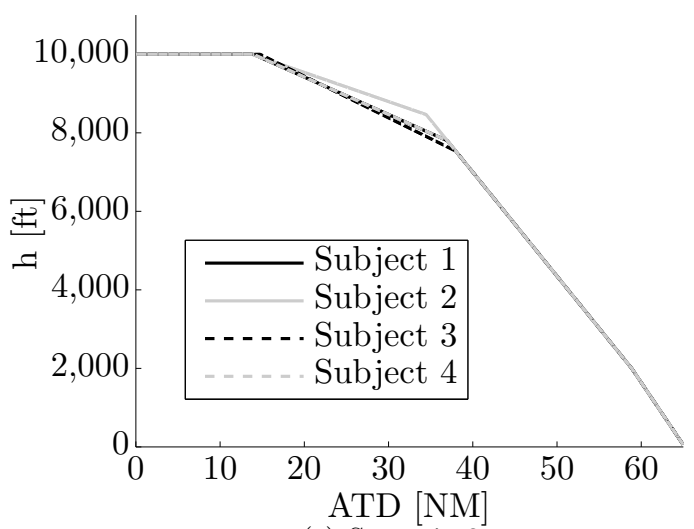

(c) Scenario 2

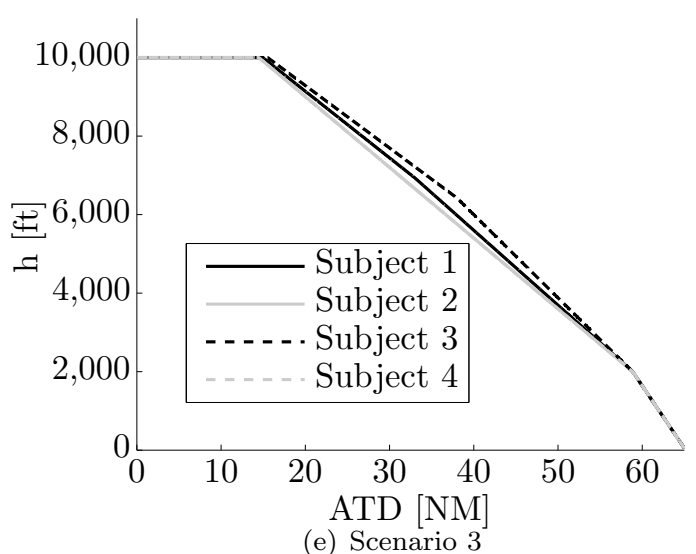

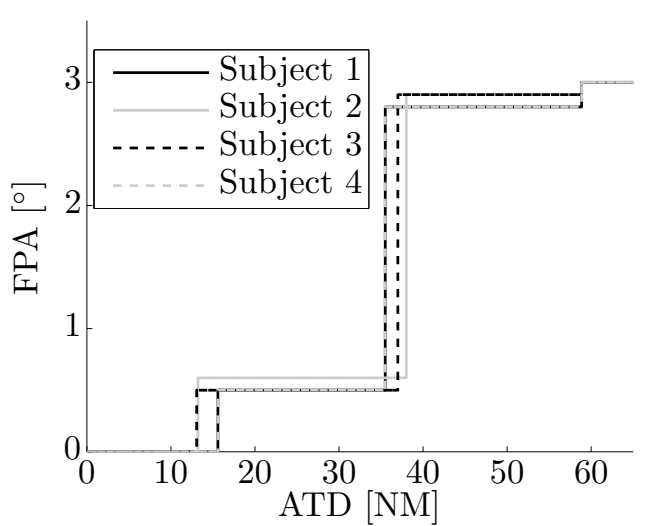

(b) Scenario 1

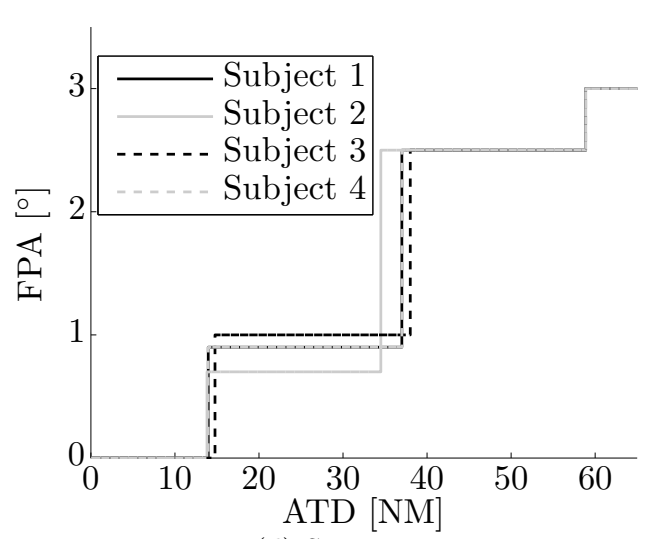

(d) Scenario 2

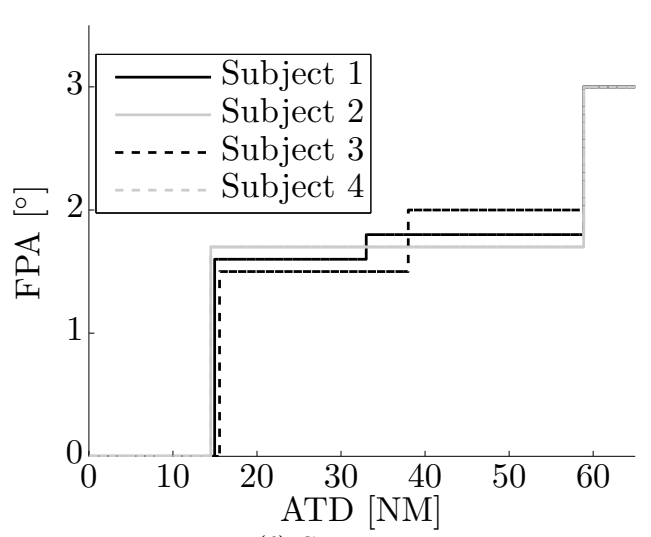

(f) Scenario 3

Figure 13. Selected approach profiles

whereas a negative number indicates an early ATA.

As can be seen in the table, good performance was achieved by all subjects for Scenario 3. For Scenario 2, three out of four subjects performed well. Subject 3 tried to calculate his ETA during the execution of the approach and, as a consequence, selected Flaps 10 too early. This lead to his late arrival for this scenario.

Scenario 1 was clearly the scenario with the worst overall performance. As can be seen in Fig. 13(a), this approach had a large flight-path angle for the second segment for all subjects. As a consequence, decelerations were minimal during the execution of that segment. This lead to difficulty in timing the Flaps 10 setting, because it was difficult for the pilots to determine at which point the Flaps 10 cue was exactly aligned with the IAS. Therefore, performance for this scenario was degraded. 
Table 3. Time error at runway threshold $[\mathrm{s}]$

\begin{tabular}{lccc}
\hline \hline & Scenario 1 & Scenario 2 & Scenario 3 \\
\hline Subject 1 & +14.0 & -2.9 & -0.2 \\
Subject 2 & +9.0 & +0.3 & -0.4 \\
Subject 3 & +14.8 & +33.9 & +3.5 \\
Subject 4 & +1.7 & +0.9 & +2.0 \\
\hline \hline
\end{tabular}

\section{V.C.2. Workload}

For a first indication of workload, the subjects filled in a NASA TLX sheet after each run. From this it can be concluded that for all scenarios, mental and temporal demand were seen as the largest contributions to the workload. Physical demand and Frustration level were rated low for all scenarios.

Overall, the workload was not assessed very high for any scenario. The workload was rated approximately the same for Scenarios 1 and 2, and for Scenario 3 the workload was rated even slightly lower.

\section{V.C.3. Questionnaire}

In the questionnaire, the subjects rated the realism level of the simulation as average or realistic. One of the subjects described the realism level as "sufficient for the test".

No subjects had trouble selecting the appropriate approach during the planning phase of the experiment runs. They all selected their solutions well before any piloting action was required at the top of descent. To the question if they understood what action was required to meet the RTA, two subjects indicated that they used trial \& error to determine the right approach. The other subjects understood immediately what action was required to meet the RTA goal.

One major improvement point indicated by the subjects in the questionnaire, is the flap/gear schedule and the accompanying cues. One subject suggested to move the planned flap cues from the PFD to the ND and VSD and fix them to a distance-based point rather than an IAS-based point. Of course, these distance-based points have to match the points where the appropriate flap speed is reached, according to the flap schedule as given in Table 1. In the PFD, the flap maneuvering speeds could then be displayed, which is similar to current indications in modern cockpits. This also removes the need for the recalculation of the Flaps 10 speed at 12 NM from the runway, which was found to be unreliable by the subjects.

One subject indicated that it would be useful to add information of expected fuel burn during the planning of the trajectory. Often, multiple solutions were possible to meet the RTA goal, so additional information of fuel burn could then function as an additional decision criterion. Also, the subjects indicated that it would be useful to have information of flap/gear cues during the planning phase, so it becomes clear if there are possible problematic points, when multiple, simultaneous actions are required.

Two out of four subjects indicated that their situational awareness improved by their involvement in the planning of the trajectory. The other two subjects indicated that their situational awareness would probably be the same if the FMS had come up with the solution. One subject indicated that his situational awareness increased by flying the approach with the A/P FPA Mode. Three subjects thought it would have been the same if the path was flown with VNAV mode.

\section{Conclusions and Recommendations}

The Variable Flight-path angle Approach (VFA) is an approach procedure that uses two segments of varying flight-path angles between the top of descent and the ILS interception point. This variation in flight-path angles enables the possibility to adapt the Estimated Time of Arrival (ETA) to meet the Required Time of Arrival (RTA). This adaptation of the path is done by the pilot with the use of a pilot support interface displayed in the Vertical Situation Display (VSD).

The VFA can be a good approach procedure to implement during busy day-time hours. It eliminates high thrust level segments and reduces community noise and greenhouse gas emissions by larger idle segments compared to conventional approaches. Furthermore, it has an invariable, minimum flap schedule and as such can be easily accepted by pilots while reducing flap wear at the same time. Another advantage is that it has the potential to be easily adaptable. This is especially beneficial when additional height 
or speed constraints are received from ATC. The pilot can easily manipulate the trajectory in the VSD, with the aid of an input device available in the cockpit.

An experiment was carried out to evaluate the VFA procedure and accompanying pilot support interface. Four subjects executed five straight-in approaches each: two training runs and three scenarios with different RTA. Performance was assessed by comparing the Actual Time of Arrival (ATA) with the RTA. Performance was good for the scenarios with a low or intermediate RTA, but considerably lower for the scenario with the late RTA. For this scenario, it was difficult to select Flaps 10 at exactly the right moment, due to the slow deceleration of the aircraft.

Workload was also assessed during the experiment. Mental and temporal demand were rated as main contributors to the workload. Physical demand and frustration were rated low for all scenarios. The scenario with the early RTA was rated as the scenario with the least workload. For the other scenarios, the workload was rated approximately the same.

Two out of four subjects indicated that they thought their situational awareness increased by their involvement in the planning of the approach. The other two thought it would have been the same if the FMS would have decided the trajectory. One subject thought his situational awareness increased by flying the approach with the A/P FPA mode as opposed to flying it with VNAV mode.

For future experiments, it is recommended to adapt the flap/gear cues. It is advised to move these cues from the Primary Flight Display (PFD) to the Navigation Display (ND)/VSD and that they are based on a distance-based instead of an IAS-based point. Furthermore, turns and wind conditions can be added to the approach to increase the realism of the experiment. Also, it is advised to display current ETA information. This could drastically improve performance. It is advised to carry out a larger experiment, from which statistical data can be collected.

For this research, only two segments between top of descent and ILS intercept point has been investigated. Future research can be done to investigate the influence of including more than two segments of varying flight-path angle.

The influence of the VFA on ATC operations must also be investigated. Research on how this procedure can be implemented in future ATM operations is the central question of that investigation.

\section{References}

${ }^{1}$ Erkelens, L. J. J., "Research into new noise abatement procedures for the $21^{\text {st }}$ century," Proceedings of the AIAA Guidance, Navigation and Control Conference and Exhibit, Denver, Colorado, August 14 - 17, No. AIAA 2000-4474, 2000, pp. $1-10$.

${ }^{2}$ Wubben, F. J. M. and Busink, J. J., "Environmental benefits of continuous descent approaches at Schiphol Airport compared with conventional approach procedures," Technical Report NLR-TP-2000-275, NLR, Fokkerweg 1, Amsterdam, May 2000.

${ }^{3}$ Ruigrok, R. C. J. and Korn, B., "Combining 4D and ASAS for Efficient TMA Operations," Tech. Rep. NLR-TP2007-759, Nationaal Lucht- en Ruimtevaartlaboratorium, 2007.

${ }^{4}$ Clarke, J.-P. B., "Systems Analysis of Noise Abatement Procedures Enabled by Advanced Flight Guidance Technology," Journal of Aircraft, Vol. 37, No. 2, 2000, pp. 266-273.

${ }^{5}$ In 't Veld, A., Van Paassen, M., Mulder, M., and Clarke, J.-P., "Pilot Support for Separation Assurance during Decelerating Approaches," Proceedings of the AIAA Guidance, Navigation and Control Conference and Exhibit, Providence, Rhode Island, August 16 - 18, No. AIAA-2004-5102, 2004, pp. 1-17.

${ }^{6}$ De Gaay Fortman, W. F., Van Paassen, M. M., Mulder, M., In 't Veld, A. C., and Clarke, J.-P. B., "Implementing Time-Based Spacing for Decelerating Approaches," Journal of Aircraft, Vol. 44, No. 1, 2007, pp. 106-118.

${ }^{7}$ De Prins, J. L., Schippers, K. F. M., Mulder, M., Van Paassen, M. M., In 't Veld, A. C., and Clarke, J.-P. B., "Enhanced Self-Spacing Algorithm for Three-Degree Decelerating Approaches," Journal of Guidance, Control and Dynamics, Vol. 30, No. 2, 2007, pp. 576-590.

${ }^{8}$ De Leege, A. M. P., In 't Veld, A. C., Mulder, M., and Van Paassen, M. M., "Three-Degree Decelerating Approaches in High Density Arrival Streams," Journal of Aircraft, Vol. 46, 2009, pp. 1681-1691.

${ }^{9}$ De Jong, P. M. A., In 't Veld, A. C., De Leege, A. M. P., Van Paassen, M. M., and Mulder, M., "Control Space Analysis of Three-Degree Decelerating Approaches at Amsterdam Airport Schiphol," Proceedings of the AIAA Guidance, Navigation and Control Conference, Toronto, Ontario Canada, August 2 - 5, No. AIAA 2010-8454, 2010, pp. 1-20.

${ }^{10}$ Westerlaken, M., In 't Veld, A. C., Mulder, M., Van Paassen, M. M., and De Leege, A. M. P., "Conceptual Development of the Free-Degree Decelerating Approach," Proceedings of the AIAA Guidance, Navigation, and Control Conference, Chicago, Illinois, August 10 - 13, No. AIAA 2009-5796, 2009, pp. 1-23.

${ }^{11}$ Palmer, E., Williams, D., Prevot, T., Romahn, S., Goka, T., Smith, N., and Crane, B., "An Operational Concept for Flying FMS Trajectories in Center and TRACON Airspace," Proceedings of the $10^{\text {th }}$ International Symposium on Aviation Psychology, Columbus, Ohio, May 3-6, 1999, pp. 1-7.

${ }^{12}$ Reynolds, T. G., Ren, L., Clarke, J. P. B., Burke, A. S., and Green, M., "History, Development and Analysis of Noise Abatement Arrival Procedures for UK Airports," Proceedings of the $5^{\text {th }}$ AIAA Aircraft Technology, Integration, and Operations (ATIO) Conference, Arlington, Virginia, September 26 - 28, No. AIAA 2005-7395, 2005, pp. 1-11.

${ }^{13}$ Erkelens, L. J. J., "Advanced Noise Abatement Procedures for Approach and Departure," Proceedings of the AIAA Guidance, Navigation, and Control Conference and Exhibit, Monterey, California, August 5 - 8, No. AIAA-2002-4858, 2002.

${ }^{14}$ Air Traffic Control the Netherlands, "Aeronautical Information Publication," June 2010. 
${ }^{15}$ Ruijgrok, G. J. J., Elements of Airplane Performance, Delft University Press, 1996.

${ }^{16}$ Edwards, C., Lombaerts, T., and Smaili, H., Fault Tolerant Flight Control: A Benchmark Challenge, Springer, 2010.

${ }^{17}$ Van der Linden, C. A. A. M., DASMAT-Delft University Aircraft Simulation Model and Analysis Tool: A Matlab/Simulink Environment for Flight Dynamics and Control Analysis, Delft University Press, 1998.

${ }^{18}$ Vormer, F., Mulder, M., Van Paassen, M. M., and Mulder, J. A., "Optimization of Flexible Approach Trajectories Using a Genetic Algorithm," Journal of Aircraft, Vol. 43, No. 4, 2006, pp. 941-952.

${ }^{19}$ Boone, P., "Introduction to the B737-NG Vertical Situation Display (VSD)," Internet (http://www.b737.org.uk/ vsd.pps), July 2007, Last visited: March 21, 2011.

${ }^{20}$ Carriker, M., "Boeing 787 Dreamliner Flight Deck Safety, Comfort, Efficiency," Internet (http://selair.selkirk. ca/Training/systems/power-point/787Dreamliner.pdf), 2006, Last visited: March 21, 2011.

${ }^{21}$ Kingsley-Jones, M., "Airbus hopes A350 flightdeck offers best of both worlds with A380 technology and high commonality," Internet (http://www.flightglobal.com/articles/2006/03/28/205721/ airbus-hopes-a350-flightdeck-offers-best-of-both-worlds-with-a380-technology-and-high.html), March 2007, Last visited: March 21, 2011.

${ }^{22}$ Kerr, R. B., "Data Communications Management for the Boeing 777 Airplane," $14^{\text {th }}$ Digital Avionics Systems Conference, 1995, pp. 51-56.

${ }^{23}$ Nuic, A., Poinsot, C., Iagaru, M.-G., Gallo, E., Navarro, F. A., and Querejeta, C., "Advanced Aircraft Performance Modeling for ATM: Enhancements to the BADA Model," 24th Digital Avionics System Conference, DASC 2005, 2005, pp. 2.B.4-1 - 2.B.4-1.

${ }^{24}$ Nuic, A., User Manual for the Base of Aircraft Data (BADA) - Revision 3.5, EUROCONTROL, July 2003, EEC Note No. 11/03.

${ }^{25}$ Van Paassen, M. M., Stroosma, O., and Delatour, J., "DUECA - Data-Driven Activation in Distributed Real-Time Computation," Proceedings of the AIAA Modeling and Simulation Technologies Conference and Exhibit, Denver, Colorado, August 14 - 17, Vol. AIAA-2000-4503, 2000, pp. 1-7. 